\title{
Comment to: The Increased Cost of Ventral Hernia Recurrence: A Cost Analysis. Davila, D.G., Parikh, N., Frelich, M.J. et al. Hernia (2016) 20:811
}

\author{
B. Joob $^{1} \cdot$ V. Wiwanitkit ${ }^{2}$
}

Received: 18 December 2016/Accepted: 26 May 2017/Published online: 12 June 2017

(C) Springer-Verlag France 2017

\section{Dear Editor,}

The recent publication on "cost of ventral hernia recurrence" is very interesting [1]. Davila et al. concluded that "need for recurrent VHR adds substantially to total hospital costs and resource utilization [1]." Indeed, this result can be expected since the additional cost for surgical procedure for recurrent problem cannot be avoided. Nevertheless, there are some technical concerns on the present report. First, the indirect cost for the patient should be focused because the different surgical techniques might result in different "lost" due to absence for routine work of the patients. Second, the selection of case for open or laparoscopic procedure usually relies on patient's condition and background and this might be a hidden bias on the final cost. Third, the present report is only a cost identification without concern on the outcome of surgery. A more appropriate evaluation than simple cost identification should be "cost effectiveness" or "cost utility analysis".

This comment refers to the article available at doi:10.1007/s10029016-1515-5.

An author's reply to this comment is available at doi:10.1007/s10029017-1628-5.

B. Joob

beuyjoob@hotmail.com

1 Sanitation 1 Medical Academic Center, Bangkok, Thailand

2 Hainan Medical University, Haikou, China
Compliance with ethical standards

Funding None.

Conflict of interest None.

Ethical approval This article does not contain any studies with human participants or animals performed by any of the authors.

Informed consent Informed consent was obtained from all individual participants included in the study.

\section{Reference}

1. Davila DG, Parikh N, Frelich MJ, Goldblatt MI (2016) The increased cost of ventral hernia recurrence: a cost analysis. Hernia 20(6):811-817 